\title{
Immunoglobulin-E-Mediated Reactivity to Self Antigens: A Controversial Issue
}

\author{
Sabine Zeller ${ }^{\mathrm{a}}$ Andreas G. Glaser ${ }^{\mathrm{a}}$ Monica Vilhelmsson ${ }^{\mathrm{b}}$ Claudio Rhyner ${ }^{\mathrm{a}}$ \\ Reto Crameria

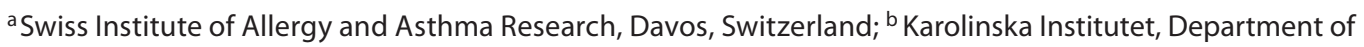 \\ Medicine, Clinical Allergy Research Unit, Stockholm, Sweden
}

\section{Key Words}

Immunoglobulin E autoreactivity · Cross-reactivity •

Self antigens $\cdot$ Molecular mimicry

\begin{abstract}
Immunoglobulin E (IgE) reactivity to self antigens is well established in vitro by ELISA, inhibition ELISA, Western blot analyses and T cell proliferation experiments. In vivo, IgEbinding self antigens are able to elicit strong type I reactions in sensitized individuals and, in the case of human manganese superoxide dismutase, to elicit eczematous reactions on healthy skin areas of patients suffering from atopic eczema. The reactions against self antigens sharing structural homology with environmental allergens can be plausibly explained by molecular mimicry between common B cell epitopes. For the second class of IgE-binding self antigens without sequence homology to known allergens, it is still unclear if the structures are able to induce a B cell switch to $\mathrm{IgE}$ production, or if the reactivity is due to sequence similarity shared with not yet detected environmental allergens. However, in all cases, cross-reactivity is never complete, indicating either a lower affinity of IgE antibodies to self allergens than to the homologous environmental allergens or the presence of additional B cell epitopes on the surface of the environmental allergens, or both. Increasing evidence shows that self allergens could play a decisive role in the
\end{abstract}

exacerbation of long-lasting atopic diseases. However, the only observation supporting a clinical role of IgE-mediated autoreactivity is confined to the fact that IgE levels against self antigens correlate with disease severity.

Copyright $\odot 2007$ S. Karger AG, Basel

\section{Introduction}

Historically, the first description of 'autoreactivity' goes back to the early last century when the sensitivity of man to human skin dander was demonstrated $[1,2]$. At that time, it was of course not possible to identify the molecular nature of the endogenous proteins potentially serving as targets for immunoglobulin E (IgE) (auto)-antibodies. For this reason, the concept that IgE-mediated autoreactivity might play a role in the pathogenesis of allergic diseases was not followed further, until progress in modern molecular biology methods allowed to identify, clone and produce IgE-binding self antigens which are expressed in a variety of human tissues and cell types [3, 4]. To date, a long list of IgE-binding self antigens has been described, and those best investigated are reported in table 1. Although IgE-mediated reactivity to self antigens has been clearly shown in vitro and in vivo [3, 5-12], it is still unclear if and how immune recognition of IgEreactive autoantigens can contribute to the pathogenesis

\section{KARGER}

Fax +41613061234

E-Mail karger@karger.ch

www.karger.com
(C) 2007 S. Karger AG, Basel

$1018-2438 / 07 / 1452-0087 \$ 23.50 / 0$

Accessible online at:

www.karger.com/iaa
Correspondence to: Prof. Dr. Reto Crameri

Department of Molecular Allergology

Swiss Institute of Allergy and Asthma Research (SIAF)

Obere Strasse 22, CH-7270 Davos (Switzerland)

Tel. +41 8141008 48, Fax +41 8141008 40, E-Mail crameri@siaf.uzh.ch 
of allergic inflammation. However, there is increasing evidence deriving from structural work comparing pairs of homologous environmental and self antigens [11-14] and from cellular work [15-17] indicating that the observed phenomenon of autoreactivity to self antigens is due to molecular mimicry between shared B cell epitopes situated at the end of the sensitization process.

\section{Allergenicity, Autoreactivity and Autoimmunity}

In order to understand complex phenomena like the ability of human manganese superoxide dismutase (MnSOD) to elicit eczema formation after application to the skin of MnSOD-sensitized individuals $[9,18]$, it is important to precisely define the terms allergenicity, autoreactivity and autoimmunity.

The allergenicity of a protein reflects two properties: (1) the potential to induce allergen-specific IgE antibodies through induction of B cell isotype switches (sensitization), and (2) the potential to induce symptoms by crosslinking of membrane-bound allergen-specific IgE on effector cells, normally reflected by a positive skin test in sensitized individuals. These two intrinsic properties of an allergen are not necessarily linked. In fact, sensitization to Api g 1, the major celery allergen which is structurally related to the major birch pollen allergen Bet $\mathrm{v} 1$ [19], is frequent in Central Europe where birch allergy is common, but not in Southern Europe where birch is absent [20]. Although celery allergy is quite common in the Mediterranean area, sensitization in this geographic area occurs through various celery allergens but not through Api g 1 [20], indicating a low allergenic potential of Api $g$ 1, if any. Cellular work involving $\mathrm{T}$ cell lines and $\mathrm{T}$ cell clones demonstrated that humoral as well as cellular reactivity to Api g 1 is predominantly based on cross-reactivity with the major birch pollen allergen Bet v $1[21,22]$. Finally, the recently solved crystal structure of Api g 1 [23] allows a deep analysis of the cross-reactivity between Api g 1 and Bet $\mathrm{v} 1$ confirming, at structural level, the predominant role of cross-reactivity in sensitization to Api g 1, earlier shown by mutational epitope analysis [24]. Together, these data clearly demonstrate that allergens like Api 1 might elicit symptoms by cross-linking the bound IgE on the surface of mast cells, although they are not able to induce the secretion of allergen-specific IgE antibodies by B cells.

Allergenicity related to the ability of a protein to induce symptoms based on cross-reactivity is a quite common phenomenon in pollen-food syndromes as indicated by the consumption of apples which rarely, if ever, induc- es IgE antibodies but may elicit allergic symptoms in patients with peach allergy or birch pollinosis [16].

Autoreactivity can be defined as an antigen-antibody response to self antigens and is not necessarily linked to an autoimmune response. Like IgE-mediated responses to pollen-food allergens, autoreactivity can occur between self antigens and structurally related environmental antigens as a result of molecular mimicry which will be discussed in detail below. In contrast, autoimmunity results from the production of autoantibodies raised against self antigens $[25,26]$.

B cell cross-reactivity, which is important for mast cell triggering, is straightforward, as it concerns only B cell epitopes. In contrast to $\mathrm{T}$ cell cross-reactivity which involves linear epitopes, B cell cross-reactivity is exquisitely dependent on conformational features [27]. Unfortunately, misconceptions regarding the term 'epitope' are widespread in the literature, probably generated through different experimental setups, as pointed out earlier by Laver et al. [28]. The only method to determine the complete structure of a B cell epitope is the preparation of a complex of a monoclonal antibody Fab fragment with its antigen, cocrystallization of the complex and determination of its structure resolving those determinants recognized by the complementary determining regions of the antibody on the native protein. All Fab/antigen complexes solved so far by X-ray crystallography reveal discontinuous B cell epitopes, including a recent study on binding and structural characterization of cross-reactive phylogenetically conserved Plasmodium proteins [29]. This study also shows that the binding affinity of the monoclonal antibody raised against the apical membrane antigen 1 from Plasmodium vivax to the homologous crossreacting apical membrane antigen 1 antigen from Plasmodium falciparum is about 100 -fold weaker compared with binding to the cognate antigen. This difference in affinity can be traced back to differences in contacts between the antibody and the homologous antigens.

Unfortunately, the common methods used to investigate cross-reactivity such as ELISA, Western blot analyses and inhibition experiments are not sensitive enough to reveal differences in antigen-antibody affinity which might have profound physiological consequences.

\section{IgE-Binding Self Antigens}

The first reported autoantigen able to bind serum IgE from allergic individuals was human profilin [5], a protein structurally related to the birch pollen allergen Bet 
Table 1. Self antigens confirmed as IgE-binding molecules in vitro and in skin test challenges in vivo

\begin{tabular}{|c|c|c|c|c|c|c|}
\hline Autoantigen & $\begin{array}{l}\text { Homologous } \\
\text { allergens }\end{array}$ & $\begin{array}{l}\mathrm{MW} \\
\mathrm{kDa}\end{array}$ & Function & $\begin{array}{l}\text { GenBank } \\
\text { Acc. No. }\end{array}$ & $\begin{array}{l}\text { PDB } \\
\text { ID }\end{array}$ & Ref. \\
\hline SART-1 (Hom s 1) & & 73 & cell cycle arrest and apoptosis & AB006198 & & 48,49 \\
\hline$\alpha-\mathrm{NAC}$ (Hom s 2) & & 33 & $\begin{array}{l}\text { intracellular localization of nascent } \\
\text { polypeptides, activator of transcription }\end{array}$ & AJ278883 & & 3,50 \\
\hline BCL7B (Hom s 3) & & 20 & oncogene & X89985 & & 3 \\
\hline Hom s 4 & $\begin{array}{l}\text { Cyp c } 1 \\
\text { Phl p } 7\end{array}$ & 54 & & Y17711 & & 3,51 \\
\hline Cytokeratin type II (Hom s 5) & & 43 & component of the cytoskeleton & & & 3 \\
\hline Profilin & Bet v 2 & 15 & actin polymerization & NM_005022 & $1 \mathrm{pfl}$ & 5 \\
\hline Ribosomal $\mathrm{P}_{2}$ & Asp f 8 & 13 & part of the $60 \mathrm{~S}$ ribosome & AJ224333 & & 7 \\
\hline MnSOD & $\begin{array}{l}\text { Asp f } 6 \\
\text { Mala s } 11 \\
\text { Hev b } 10\end{array}$ & 26 & superoxide dismutase & Y00472 & $1 \mathrm{ABM}$ & 13 \\
\hline Cyclophilin B & $\begin{array}{l}\text { Asp f } 27 \\
\text { Asp f } 11 \\
\text { Mala s } 6\end{array}$ & 23 & peptidyl-prolyl cis-trans isomerase & NM_000942 & $2 \mathrm{CPL}$ & 11 \\
\hline Thioredoxin & $\begin{array}{l}\text { Mala s } 13 \\
\text { Tri a } 25 \\
\text { Zea m } 25 \\
\text { ZmTRXh2 }\end{array}$ & 12 & oxidoreductase & $\begin{array}{l}\text { X77584 } \\
\text { NM_003329 }\end{array}$ & 1ERU & 12 \\
\hline
\end{tabular}

MW = Molecular weight; PDB ID = Protein Data Bank identification.

v 2. It was demonstrated that profilins constitute a wide family of pan-allergens [30]; however, human profilin was not able to induce immediate type I reactions in skin test challenges of allergic individuals sensitized to Bet v 2 [4]. A plausible explanation for this observation could be that the affinity of the cross-reactive IgE antibodies raised against Bet $\mathrm{v} 2$ is not high enough for human profilin to induce mast cell degranulation. In contrast, many other self antigens like MnSOD [6], ribosomal $\mathrm{P}_{2}$ protein [7], cyclophilin $(\mathrm{CyP})[8,11]$ and thioredoxin $[10,12]$, which all show a strong structural similarity to environmental allergens, as well as self antigens without structural similarity to environmental allergens like cytokeratin type II or BCL7B [3] clearly elicit positive results in skin test challenges (table 1). However, the number of IgE-binding self antigens is certainly much larger than those described so far. High throughput screening of a human lung cDNA library displayed on phage surface $[31,32]$ revealed more than 150 partial and complete cDNA sequences potentially encoding IgE-binding proteins. Although not yet analyzed in detail, some of the cDNA sequences, like those encoding $\alpha$-tubulin [33] or ribosomal $\mathrm{L}_{3}$ protein [34], show a high degree of sequence identity and cross-reactivity to environmental allergens [Zeller et al., unpublished results]. In these cases, it makes sense to assume that $\operatorname{IgE}$ autoreactivity can be traced back to common structural features shared between environmental and self antigens (see below). However, structural similarity of the environmental allergen should probably not be too similar to the corresponding human antigen as strongly autoreactive B cells can be expected to be deleted from the repertoire $[16,35]$. Although the repertoire of allergenic structures is supposed to be limited [36], it is unfortunately far from complete. This unsatisfactory situation does not allow a bioinformatic evaluation of cDNA sequences without homology to known environmental allergens for their cross-reactive potential. 


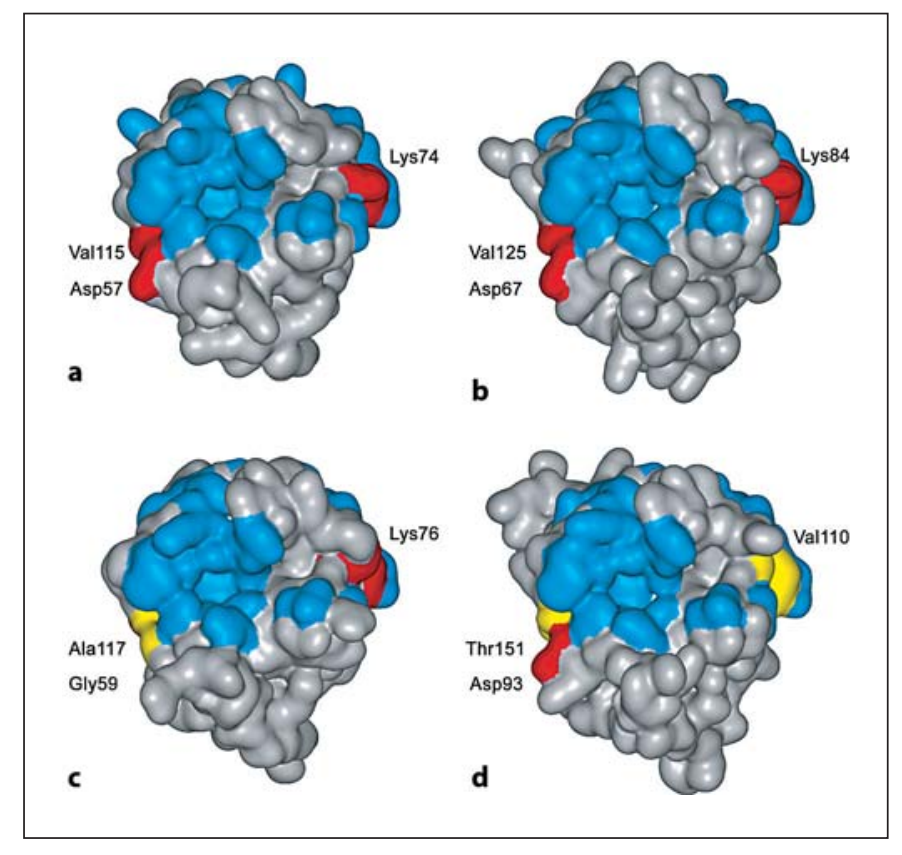

Fig. 1. Solvent exposed surfaces of Mala s 6 and the natural human isoforms CyP B, CyP A and CyP C. Amino acids which are conserved in all structures and exposed to the solvent define two putative IgE-binding epitopes (blue). Asp57 of Mala s 6 which corresponds to Asp67 of Cyp B and Asp93 of CyP C is mutated to Gly59 in the sequence of CyP A. Lys74 of Mala s 6 corresponds to Lys84 in CyP B and Lys76 in CyP A, but is mutated to Val110 in CyP C. Further, Val115 of Mala s 6, which corresponds to Val125 in CyP B is mutated in CyP A and CyP C to Ala117 and Thr151, respectively. These mutations (yellow) reduce the size of the putative cross-reactive $\mathrm{B}$ cell epitopes, and therefore, may explain the reduced IgE-binding capacity of CyP A and CyP C compared with $\mathrm{CyP} \mathrm{B}$ as seen in inhibition ELISA experiments.

\section{The Structural Basis of Cross-Reactivity}

Recently, the 3D structures of many allergens have been solved [37], allowing detailed comparisons between homologous structures. With respect to cross-reactivity to self antigens, the most interesting structures are those allowing a pair-wise comparison between the environmental and the corresponding human protein. MnSOD $[6,9,13], \mathrm{CyP}[8,11]$ and thioredoxin $[12]$ belong to this class, and the most exciting example is, perhaps, CyP. CyPs constitute a family of cytosolic proteins which play a pivotal role in protein folding through enzymatic catalysis of the peptidyl-prolyl cis-trans isomerization reaction [38]. The primary structure of this important enzyme is highly conserved among phylogenetically distant species, indicating the involvement of $\mathrm{CyP}$ in basic cellular functions [39]. CyP was first reported to be an al- lergen (Psi c 2) isolated from the basidiomycete Psilocybe cubensis [40], and later, from phage surface-displayed libraries of Aspergillus fumigatus (Asp f 11, Asp f 27) [11, 14], Candida albicans [8] and Malassezia sympodialis (Mala s 6) $[8,41]$. CyP as allergen is not limited to the fungal kingdom but is also described as an allergen from various pollens [42] and foods [43].

The crystal structure of M. symodialis CyP (Mala s 6) has now been solved at $1.50 \AA$ resolution [11]. Together with the solved structures of the homologous human CyPs, the new structure allows an exact comparison of the spatial orientation of conserved amino acids between self/non-self antigens. On the structural level, Mala s 6 and human CyPs superpose well with a root mean square deviation of $1.05 \AA$ for all $\mathrm{C} \alpha$ atoms of the protein backbone. Because Mala s 6 and human CyPs show cross-reactivity in Western blot analyses [8], ELISA and skin challenges [11], they must share common IgE-binding epitopes. Obviously, only those residues that are identical in pairs of allergens and at least partly exposed to the solvent can contribute to the binding of cross-reactive $\operatorname{IgE}$ antibodies in native proteins. Thus, solvent-accessible residues conserved in both proteins are potentially involved in IgE-mediated cross-reactivity. Although the sequence identity between Mala s 6, human CyP A, CyP B and CyP $\mathrm{C}$ reach values of 71,63 and $60 \%$ at primary structure level, respectively, only a very limited number of identical amino acids are exposed to the solvent in correctly folded protein pairs (fig. 1). The conserved surface-exposed residues are scattered over the whole sequence and are thus likely to define the discontinuous structures found in B cell epitopes. In the 3D models of the correctly folded proteins, these amino acids are clustered over the surfaces forming patches covering solvent-accessible surface areas which involve 15-22 amino acid residues on different surface loops occupying a buried surface compatible with the structure of a B cell epitope [11].

Binding of serum IgE to CyPs was determined by ELISA, and cross-reactivity was demonstrated in competitive inhibition ELISA (fig. 2). However, the observed cross-reactivity between fungal and human CyPs, as deduced from ELISA inhibition experiments using single patients' sera, ranges between 60 and $30 \%$ which is not compatible with a complete cross-reactivity. Interestingly, the strongest inhibition was obtained with human CyP $\mathrm{B}$ which shares the highest number of identical amino acids exposed to the solvent with Mala s 6, followed by human $\mathrm{CyP} A$ and human $\mathrm{CyP} \mathrm{C}$, as shown in figure 1 . This might indicate that the cross-reactive epitopes bind IgE with a lower affinity depending on the number of 
shared identical amino acids which determine the number of possible contacts that can be established between the allergen and the complementary determining regions of the antibodies. However, this approach is not suitable to answer the question whether the partial cross-reactivity observed between Mala s 6 and human CyPs is due to differences in affinity or to the lack of additional epitopes which could be present in the sensitizing allergen.

\section{Clinical Relevance of Self Antigens}

Autoreactivity to human proteins has been postulated as a pathogenic factor in atopic eczema (AE) based on the detection of IgE antibodies directed against various proteins in vivo [44]. There is no doubt that a variety of human proteins can induce strong B- and T-cell-mediated responses in peripheral blood mononuclear cells of patients suffering from chronic inflammatory allergic diseases [6-12]. Intradermal and skin prick tests demonstrate that self antigens are able to induce IgE cross-linking on the surface of effector cells in vivo. However, a positive dermal challenge test does not necessarily correlate with clinical symptoms since up to $40 \%$ of the individuals sensitized to environmental allergens are asymptomatic [45]. Therefore, skin test challenges with self antigens are useful to demonstrate cross-reactivity with homologous recombinant allergens or direct sensitization to the self antigen, but not for the demonstration of the clinical relevance. Although it makes sense to assume that self antigen-induced mediator release in vivo could have clinical consequences at least for a subset of the patients, we presently do not have any suitable test to unequivocally demonstrate an involvement of self antigens in the pathogenesis of allergic diseases.

Probably the most reliable indication for a role of self antigens in the pathogenesis of allergic diseases comes from atopy patch tests performed with human MnSOD in patients suffering from $\mathrm{AE}[9,46]$. This study showed that human MnSOD - a stress-inducible enzyme - is able to induce eczematous reactions on unaffected skin areas of AE patients sensitized to M. sympodialis. In concordance with the presence of MnSOD-specific IgE, the human enzyme also elicited positive skin prick test reactions and $\mathrm{T}$ cell proliferation in all ELISA-positive patients. Interestingly, reactivity against human MnSOD strongly correlated with the severity of the disease, further corroborating the postulated pathogenic role of self-reactivity in the exacerbation of AE [9]. A further indication that such reactions might contribute to the pathogenesis of $\mathrm{AE} \mathrm{de}$ -

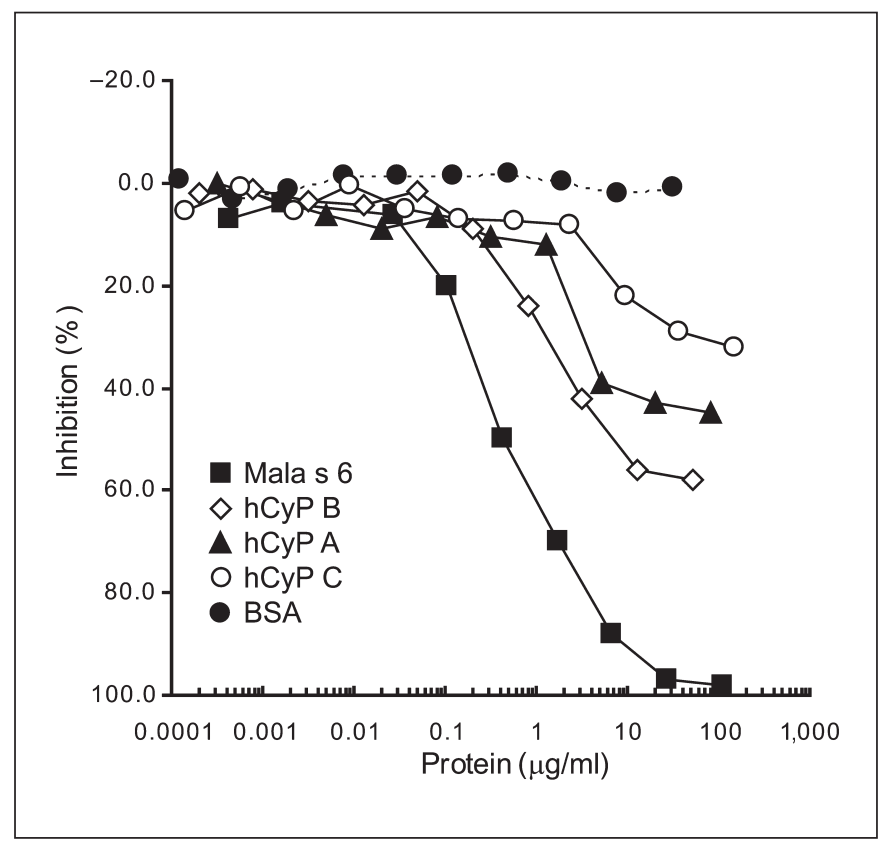

Fig. 2. Inhibition of IgE binding to solid phase-coated Mala s 6, with Mala s 6, homologous human CyPs and BSA as a negative control. Serum of a Mala s 6 sensitized patient was preincubated with increasing concentrations of Mala s 6, human CyP B, СyP A, $\mathrm{CyP} C$ and BSA as negative control. After transfer of the preincubated serum to Mala s 6 coated wells, the residual IgE binding was detected by ELISA. Apparently, all human CyPs are able to inhibit the binding of IgE to Mala s 6, indicating that Mala s 6 and the homologous human proteins share common cross-reactive IgE-binding epitopes. The reduced capacity to inhibit the IgE binding to Mala s 6 of CyP A and CyP C compared with CyP B can be explained on the structural level of these proteins.

rives from the observation that human MnSOD is upregulated in eczematous areas as shown by immunohistochemistry, most likely as a consequence of mechanical stress due to scratching. Interestingly, also CyPs and thioredoxins represent stress-inducible enzymes which are upregulated as a consequence of cellular stress. Oxidative stress could, through upregulation of nuclear factor- $\kappa \mathrm{B}$ expression, induce interleukin-4 production [47] and, as a consequence thereof, accentuate Th 2 responses to allergens and homologous self antigens.

\section{Concluding Remarks}

Evidence is increasing that self antigens are a contributing factor to the exacerbation of long-standing, inflammatory atopic diseases. Structural data provide information allowing a rational explanation of cross-reactivity 
between environmental allergens and structurally related self antigens. There is no doubt that structural features which are shared between self antigens such as MnSOD, CyPs and thioredoxin and homologous environmental (pan)-allergens are responsible for the common IgEbinding capacity observed in Western blot analyses, ELISA and competitive inhibition ELISA, as well as for their ability to elicit positive skin or atopy patch tests. Crossreactivity between these molecules is never complete, indicating that either environmental allergens elicit, beside cross-reactive, additional IgE-binding epitopes, or that the $B$ cell epitopes displayed on the surface of self antigens have a reduced IgE-binding affinity. Either reason or their combination could be sufficient to explain the reduced IgE-binding capability of self antigens compared with their homologous environmental allergens. In contrast to the cross-reactivity between human and homologous environmental allergens which was studied in deep detail, not much is known about the autoreactivity of self antigens without sequence homology to environmental allergens. It is still not clear if they are able to directly induce a B cell switch towards IgE production, or if the observed IgE-binding capability is due to cross-reactivity with not yet identified environmental allergen structures. However, clear evidences showing that autoreactivity could be a pathogenic factor for severe chronic allergic diseases are still lacking, and the only indication that this could be the case is limited to the observation that the levels of IgE autoantibodies in AE patients correlate to the severity of the disease.

\section{Acknowledgments}

This work was supported by the Swiss National Science Foundation (grants 3100-63381/2 and 31000-114634/1) and by the OPO-Pharma Foundation, Zürich, Switzerland.

\section{References}

$>1$ Keller P: Beitrag zu den Beziehungen von Asthma und Ekzem. Arch Derm Syph Berl 1924;148:82-91.

$\checkmark 2$ Hampton SF, Cooke RA: The sensitivity of man to human dander, with particular reference to eczema (allergic dermatitis). J Allergy 1941;13:63-76.

>3 Natter S, Seiberler S, Hufnagl P, Binder BR, Hirschl AM, Ring J, Abeck D, Schmidt T, Valent P, Valenta R: Isolation of cDNA clones coding for IgE autoantigens with serum IgE from atopic dermatitis patients. FASEB J 1998;12:1559-1569.

4 Appenzeller U, Mayer C, Menz G, Blaser K, Crameri R: IgE-mediated reactions to autoantigens in allergic diseases. Int Arch Allergy Immunol 1999;118:193-196.

5 Valenta R, Duchêne M, Pettenburger K, Sillaber C, Valent P, Bettelheim P, Breitenbach M, Rumpold H, Kraft D, Scheiner O: Identification of profiling as a novel allergen: $\operatorname{IgE}$ autoreactivity in sensitized individuals. Science 1991;253:557-560.

6 Crameri R, Faith A, Hemmann S, Jaussi R, Ismail C, Menz G, Blaser K: Humoral and cell mediated autoimmunity in allergy to $A s-$ pergillus fumigatus. J Exp Med 1996;184: 256-270.

7 Mayer C, Appenzeller U, Seelbach H, Achatz G, Oberkofler H, Breitenbach M, Blaser K, Crameri R: Humoral and cell-mediated autoimmune reactions to human acidic ribosomal $\mathrm{P}_{2}$ protein in individuals sensitized to Aspergillus fumigatus $\mathrm{P}_{2}$ protein. J Exp Med 1999;189:1507-1512.
${ }_{8}$ Flückiger S, Fijten H, Whitley P, Blaser K, Crameri R: Cyclophilins, a new family of cross-reactive allergens. Eur J Immunol 2002;32:10-17.

-9 Schmid-Grendelmeier C, Flückiger S, Disch $\mathrm{R}$, Trautmann A, Wüthrich B, Blaser K, Scheynius A, Crameri R: IgE-mediated and T cell-mediated autoimmunity against manganese superoxide dismutase in atopic dermatitis. J Allergy Clin Immunol 2005; 115 : 1068-1075.

$>10$ Weichel M, Glaser AG, Ballmer-Weber BK, Schmid-Grendelmeier P, Crameri R: Wheat and maize thioredoxins: a novel cross-reactive cereal allergen family related to baker's asthma. J Allergy Clin Immunol 2006;117: 676-681.

11 Glaser AG, Limacher A, Flückiger S, Scheynius A, Scapozza L, Crameri R: Analysis of the cross-reactivity and of the $1.5 \AA$ crystal structure of the Malassezia sympodialis Mala s 6 allergen, a member of the cyclophilin pan-allergen family. Biochem J 2006;396:41-49.

12 Limacher A, Glaser AG, Meier C, SchmidGrendelmeier P, Zeller S, Scapozza L, Crameri R: Cross-reactivity and 1.4 crystal structure of Malassezia sympodialis thioredoxin (Mala s 13), a member of a new pan-allergen family. J Immunol 2007;178:389-396.
13 Flückger S, Mittl PRE, Scapozza S, Fijten H, Folkers G, Grütter MG, Blaser K, Crameri R: Comparison of the crystal structures of the human manganese superoxide dismutase and the homologous Aspergillus fumigatus allergen at $2 \AA$ resolution. J Immunol 2002; 168:1267-1272.

$>14$ Limacher A, Kloer DP, Flückiger S, Folkers G, Crameri R, Scapozza L: The crystal structure of Aspergillus fumigatus cyclophilin reveals 3D domain swapping of a central element. Structure 2006;14:185-195.

15 Flückiger S, Scapozza L, Mayer C, Blaser K, Folkers G, Crameri R: Immunological and structural analysis of IgE-mediated cross-reactivity between manganese superoxide dismutases. Int Arch Allergy Immunol 2002; 128:292-303.

16 Aalberse RC: Structural features of allergenic molecules. Chem Immunol Allergy 2006; 91:134-146.

17 Vilhelmsson M, Johansson C, Jacobsson-Ekman G, Crameri R, Zargari A, Scheynius A: The Malassezia sympodialis allergen Mala s 11 induces human dendritic cell maturation, in contrast to its human homologue manganese superoxide dismutase. Int Arch Allergy Immunol 2007;143:155-162.

18 Schmid-Grendelmeier P, Scheynius A, Crameri R: The role of sensitization to Malassezia sympodialis in atopic eczema. Chem Immunol Allergy 2006;91:98-109. 
19 Breiteneder H, Hoffmann-Sommergruber K, O’Riordain G, Susani M, Ahorn H, Ebner C, Kraft D, Scheiner O: Molecular characterization of Api g 1, the major allergen of celery (Apium graveolens), and its immunological and structural relationships to a group of 17$\mathrm{kDa}$ tree pollen allergens. Eur J Biochem 1995;233:484-489.

20 Hoffmann-Sommergruber K, Demoly P, Crameri R, Breiteneder H, Ebner C, Laimer Da Camara Machado M, Blaser K, Ismail C, Scheiner O, Bousquet J, Menz G: IgE reactivity to Api g 1, a major celery allergen, in a central European population is based on primary sensitization by Bet v 1 . J Allergy Clin Immunol 1999;104:478-484.

-21 Bohle B, Radakovics A, Jahn-Schmid B, Hoffmann-Sommergruber K, Fischer GF, Ebner C: Bet v 1, the major brich pollen allergen, initiates sensitization to Api g 1, the major allergen in celery. Evidence at the $\mathrm{T}$ cell level. Eur J Immunol 2003;33:33033310.

-22 Jahn-Schmid B, Radakovics A, Luffkopf D, Scheurer S, Vieths S, Ebner C, Bohle B: Bet v 1 142-146 is the dominant T-cell epitope of the major birch pollen allergen and important for cross-reactivity with Bet v 1-related food allergens. J Allergy Clin Immunol 2005; 116:213-219.

-23 Schirmer T, Hoffmann-Sommergruber K, Susani M, Breiteneder H, Markovic-Housley $\mathrm{Z}$ : Crystal structure of the major celery allergen Api g 1: molecular analysis of crossreactivity. J Mol Biol 2005;351:1101-1109.

-24 Neudecker P, Lehmann K, Nerkamp J, Haase T, Wangrosch A, Fötisch K, Hoffmann S, Rösch P, Vieths, S, Scheurer S: Mutational epitope analysis of Pur av 1 and Api g 1, the major allergens of cherry (Prunus avium) and celery (Apium graveolens): correlating IgE reactivity with three-dimensional structure. Biochem J 2003;376:97-107.

-25 Theofilopoulos AN, Kono DH: The genes of systemic autoimmunity. Proc Assoc Am Physicians 1999;111:228-240.

26 Mackay IR, Rowley MJ: Autoimmune epitopes: autoepitopes. Autoimmun Rev 2004;3: 487-492.

-27 Crameri R: Correlating IgE reactivity with three-dimensional structure. Biochem J 2003;376:e1-e2.

-28 Laver WG, Air GM, Webster RG, Smith-Gill SJ: Epitopes on protein antigens: misconceptions and realities. Cell 1990;61:553-556.
29 Igonet S, Vulliez-Le Normand B, Faure G, Riottot MM, Kocken CH, Thomas AW, Bentley GA: Cross-reactivity studies on an antiPlasmodium vivax apical membrane antigen 1 monoclonal antibody: binding and structural characterisation. J Mol Biol 2007;366: 1523-1527.

30 Valenta R, Duchene M, Ebner C, Valent P, Sillaber C, Deviller P, et al: Profilins constitute a novel family of functional plant panallergens. J Exp Med 1992;175:377-385.

31 Kodzius R, Rhyner C, Konthur Z, Buczek D, Lehrach H, Walter G, Crameri R: Rapid identification of allergen-encoding cDNA clones by phage display and high-density arrays Comb Chem High Throughput Screen 2003 6:147-154

32 Crameri R, Kodzius R, Konthur Z, Lehrach $\mathrm{H}$, Blaser K, Walter G: Tapping allergen repertoires by advanced cloning technologies. Int Arch Allergy Immunol 2001;124:43-47.

-33 Saarne T, Kaiser L, Rasool O, Huecas S, van Hage-Hamsten M, Gafvelin G: Cloning and characterisation of two IgE-binding proteins, homologous to tropomyosin and $\alpha$-tubulin, from the mite Lepidoglyphus destructor. Int Arch Allergy Immunol 2003;130: 258-265.

34 Saxena S, Madan T, Muralidhar K, Sarma PU: cDNA cloning, expression and characterization of an allergenic $\mathrm{L}_{3}$ ribosomal protein of Aspergillus fumigatus. Clin Exp Immunol 2003;134:86-91.

35 Aalberse RC: Structural biology of allergens J Allergy Clin Immunol 2000;105:228-238.

36 Stadler MB, Stadler BM: Allergenicity prediction by protein sequence. FASEB J 2003; 17:1141-1143.

37 Flückiger S, Limacher A, Glaser AG, Scapozza L, Crameri R: Structural aspects of crossreactive allergens. Rec Res Devel Allergy Clin Immunol 2004;5:57-75.

-38 Kakahashi N, Hayano T, Suzuki M: Peptidylprolyl cis-trans isomerase is the cyclosporine A-binding protein cyclophilin. Nature 1989; 377:473-475.

39 Trandinh CC, Pao GM, Saier MH: Structural and evolutionary relationships among the immunophilins: two ubiquitous families of peptidyl-prolyl cis-trans isomerases. FASEB J 1992;6:3410-3420.

40 Horner WE, Reese G, Lehrer SB: Identification of the allergen Psi c 2 from the basidiomycete Psilocybe cubensis as a fungal cyclophilin. Int Arch Allergy Immunol 1995; 107:298-300.

-41 Lindborg M, Magnusson CG, Zargari A, Schmidt M, Scheynius A, Crameri R, Whitley P: Selective cloning of allergens from the skin colonizing yeast Malassezia furfur by phage surface display technology. J Invest Dermatol 1999;113:156-161.
42 Cadot P, Nelles L, Srahna M, Dilissen E, Ceuppens JL: Cloning and expression of the cyclophilin Bet v 7, and the analysis of immunological cross-reactivity among the cyclophilin A family. Mol Immunol 2006;43: 226-235.

43 Fujita C, Moriyama T, Ogawa T: Identification of cyclophilin as an IgE-binding protein from carrots. Int Arch Allergy Immunol 2001;125:44-50.

44 Mittermann I, Aichberger KJ, Bunder R, Mothes N, Renz H, Valenta R: Autoimmunity and atopic dermatitis. Curr Opin Allergy Clin Immunol 2004;4:367-371.

45 Bousquet J, Anto JM, Bachert C, Bousquet PJ, Colombo P, Crameri R, et al: Factors responsible for differences between asymptomatic subjects and patients presenting an IgE sensitization to allergens. A GA ${ }^{2} \mathrm{LEN}$ project. Allergy 2006;61:671-680.

46 Schmid-Grendelmeier P, Scheynius A, Crameri R: The role of sensitization to Malassezia sympodialis in atopic eczema. Chem Immunol Allergy 2006;91:98-109.

$47 \mathrm{Wu}$ Z, MacPhee IA, Oliveira DB: Reactive oxygen species in the initiation of IL-4 driven autoimmunity as a potential therapeutic target. Curr Pharm Dis 2004;10:899-913.

48 Valenta R, Natter S, Seiberler S, Wichlas S, Maurer D, Hess M, Pavelka M, Grote M, Ferreira F, Szepfalusi Z, Valent P, Stingl G: Molecular characterization of an autoallergen, Hom s 1, identified by serum IgE from atopic dermatitis patients. J Invest Dermatol 1998;111:1178-1183.

49 Hosokawa M, Kadota R, Shichijo S, Itoh K, Dmitriev I, Krasnykh V, Curiel DT, Takue Y, Wakasugi H, Takashima S, Heike Y: Cell cycle arrest and apoptosis induced by SART-1 gene transduction. Anticancer Res 2005;25: 1983-1990.

50 Mossabeb R, Seiberler S, Mittermann I, Reininger R, Spitzauer S, Natter S, Verdino P, Keller W, Kraft D, Valenta R: Characterization of a novel isoform of $\alpha$-nascent polypeptide-associated complex as IgE-defined autoantigen. J Invest Dermatol 2002;119: 820-829.

51 Aichberger KJ, Mittermann I, Reininger R, Seiberler S, Swoboda I, Spitzauer S, Kopp T, Stingl G, Sperr WR, Valent P, Repa A, Bohle B, Kraft D, Valenta R: Hom s 4, an IgE-reactive autoantigen belonging to a new subfamily of calcium-binding proteins, can induce Th cell type 1-mediated autoreactivity. J Immunol 2005;175:1286-1294. 